\title{
TRIBUNA
}

\section{(IN)SUFICIENTE FUNDAMENTO LEGAL PARA LA PROPUESTA DE REFORMA DEL REGLAMENTO 883/2004 PRESENTADA POR LA COMISÓN EUROPEA EL 13.12.2016}

\author{
(IN)SUFFICIENT LEGAL BASIS FOR THE PROPOSAL FOR REFORM \\ OF REGULATION 883/2004 PRESENTED BY THE EUROPEAN \\ COMMISSION ON 13.12.2016
}

\section{CRISTINA SÁNCHEZ-RODAS NAVARRO}

Directora de la Revista Internacional de la Protección Social

El artículo 48 del Tratado de Funcionamiento de la Unión Europea (TFUE) atribuye al Consejo la misión de establecer un régimen que permita que los trabajadores migrantes evitar los obstáculos que puedan derivarse para ellos de las normas nacionales dictadas en el ámbito de la seguridad social. Para superar esos escollos se promulgaron los Reglamentos de coordinación de sistemas de Seguridad Social, que inicialmente sólo se aplicaron a los trabajadores por cuenta ajena, funcionarios y trabajadores por cuenta propia.

Con el paso de los años el ámbito de aplicación personal se fue extendiendo hasta llegar al momento actual en el que el Reglamento 883/2004 en su artículo 2 -frente al artículo 2 del Reglamento 1408/71- incluyó dentro de su ámbito de aplicación no sólo a las ciudadanos de un Estado miembro económicamente activas, sino también a las no activas.

Pero puesto que la coordinación de sistemas no Seguridad Social nunca ha sido un fin en sí mismo sino un instrumento para garantizar la libre circulación de trabajadores, dice bien el propio Considerando $\mathrm{n}^{\circ} 2$ del vigente Reglamento 883/2004 cuando afirma que "para adoptar las medidas apropiadas en el ámbito de la Seguridad Social para las personas distintas de los trabajadores por cuenta ajena, el Tratado no prevé más poderes de acción que los mencionados en su artículo 308 -actual 352 del TFUE ${ }^{2}$. Y es por ello que para la promulgación del Reglamento 883/2004 se recurrió a un doble fundamento: el artículo 48 del TFUE y el 308 (actual 352).

Por tanto, puesto que la propuesta de Reforma del Reglamento 883/2004 de 13.12.2016 que afecta de plano a las personas no activas y a las que no son demandantes de empleopresentada por la Comisión tiene como único fundamento legal el artículo 48 del TFUE,

\footnotetext{
${ }^{1}$ El contenido de la presente tribuna refleja alguna de las conclusiones de mi artículo "El Polisémico Concepto de Asistencia Social en el Derecho de la Unión Europea y sus Efectos sobre la Propuesta de Reforma del Reglamento 883/2004: ¿Un paso atrás en la Consecución del Pilar Europeo de Derechos Sociales. Revista del Ministerio de Empleo?(en prensa).

${ }^{2 “ C u a n d o ~ s e ~ c o n s i d e r e ~ n e c e s a r i a ~ u n a ~ a c c i o ́ n ~ d e ~ l a ~ U n i o ́ n ~ e n ~ e l ~ a ́ m b i t o ~ d e ~ l a s ~ p o l i ́ t i c a s ~ d e f i n i d a s ~ e n ~ l o s ~}$ Tratados para alcanzar uno de los objetivos fijados por éstos, sin que se hayan previsto en ellos los poderes de actuación necesarios a tal efecto, el Consejo adoptará las disposiciones adecuadas por unanimidad, a propuesta de la Comisión y previa aprobación del Parlamento Europeo. Cuando el Consejo adopte dichas disposiciones con arreglo a un procedimiento legislativo especial, se pronunciará también por unanimidad, a propuesta de la Comisión y previa aprobación del Parlamento Europeo".
}

e-Revista Internacional de la Protección Social, ISNN 2445-3269. 2017, Vol. II, No 2

http://dx.doi.org/10.12795/e-RIPS.2017.i02.01.

Página 1 
hay que concluir que dicho artículo, por sí solo, no es base legal suficiente para acometer una reforma restrictiva de los derechos de las personas no activas ni demandantes de empleo, a las que el artículo 48 TFUE no resulta, además, aplicable puesto que su derecho a la libre circulación deriva del artículo 21 del TFUE. 